\title{
Implementation of Backpropagation Neural Network Method in Classification System of Timeliness of Graduation
}

\author{
$1^{\text {st }}$ Yanuar Nurdiansyah ${ }^{1}, 2^{\text {nd }}$ Diksi Media $^{2}, 3^{\text {th }}$ Fadhel Akhmad Hizam $^{3}$ \\ \{yanuar_pssi@unej.ac.id ${ }^{1}$, diksy@unej.ac.id ${ }^{2}$, hizhamfadhel@gmail.com ${ }^{3}$ \} \\ Universitas Jember (UNEJ), Indonesia ${ }^{1,2,3}$
}

\begin{abstract}
Information Systems is one of the study programs at the University of Jember which was established since 2009. To earn a degree of bachelor, students must pass 144 credits of 4-5 years study period. Method for classifying using an artificial neural network of Backpropagation. Attribute used for classification is 9 attributes, namely Grade Point Average (GPA) from 1 to 6 semester, the number of credits taken, the last semester taking Student Study Service (KKN) and Internship (PKL). Class used for the classification is the timeliness of graduation. The implementation of this classification method is done by learning rate $0.1,0.3,0.5,0.7$, and 0.9 with the iteration limit of 1,000 , 2,000 , and 3,000. The highest accuracy is $98.82 \%$ for the 2000 and 3000 , each with learning rate $=0.7$ and 0.9 for the $2000^{\text {th }}$ iteration and learning rate $=0.5,0.7$ and 0,9 for the $3000^{\text {th }}$ iteration.
\end{abstract}

Keywords: Data Mining, Classification, Artificial Neural Network, Backpropagation Neural Network Method

\section{Introduction}

The concept of data mining is the concept of exploring and analyzing large amounts of data to identify the hidden pattern. Such a concept is often used by researchers to analyze information. A concept of data mining that is often used as the initial step in decision making is classification. Classification is often used to identify a model which describes and differentiates classes, which aims to estimate the class of objects of which class are unidentified,[1], [2].

Information Systems is one of the study programs at the Universitas Jember which was established in 2009. Currently, there are many students who have earned a bachelor degree, especially from 2009 to 2013 . However, only a few have successfully completed their studies on time. Students must pass 144 credits of $4-5$ years of the study period in order to earn a degree of bachelor (UNEJ, 2015). Therefore, students are considered to graduate on time if their study period is less than or equal to 5 years (60 months).

Based on the issue, there are various methods to increase the percentage of timeliness of graduation. The classification uses the principle of data mining, especially the Naïve Bayes classification method [3], [4],[5].

A study entitled "Data Mining Using the Naïve Bayes Algorithm for Graduate Classification of Universitas Dian Nuswantoro" implemented the Naïve Bayes method to identify the 
timeliness of graduation of the Faculty of Computer Science in 2009 of DIII and S1 students [6]. The attributes used are Student Identification Number (NIM), Name, Level, Study Progam, Origin, Gender, Credit Unit, GPA, and Year of Graduation. The result shows that the level of accuracy using the Naïve Bayes classification model is $82.08 \%$, which means that the accuracy model is well proven, but further review remains needed both in terms of complexity and number of data sets.

Based on the previous studies, the researchers conducted a study on "Implementation of Backpropagation Neural Network Method (BNN) in the Classification System for the Timeliness of Graduation (Case Study: Information System Study Program of Universitas Jember)". BNN is employed because the researchers would like to identify the BNN method in classifying the timeliness of graduation at the Information System Study Program of Universitas Jember. In addition, the researchers would also like to identify the accuracy level in the implementation of the method.

\subsection{Artificial Neural Network}

The artificial neural network is a computational method which emulates biological neural networks. This method uses basic non-linear calculation so-called neuron and is interconnected to resemble human neural network. The artificial neural network is created to solve the issue of pattern recognition or classification[7].

The artificial neural network is not programmed to produce a certain output because it is based on the learning process. During the learning process, the artificial neural network includes the patterns of input (and output) and the network is programmed to provide acceptable answers [8],[9].

The artificial neural network principle is determined by three basic elements of the neural model [8]. They are:

1. A set of synapses or links that are each classified in terms of weight or strength.

2. An enhancer to add input signals weighed from the synaptic strength of each neuron.

3. An activation function to limit the output amplitude of a neuron. This function aims to limit the amplitude-distance allowed by the output signal to be a limited number.

\subsection{Backpropagation Neural Network (BNN) Method}

BNN is a supervised training algorithm consisting of layers. It uses an error output to change its weight value backward. To obtain the error, the forward propagation is firstly conducted.

Recognition method is the process of initializing data that is further processed by BNN. The data to be identified is presented in the form of a vector. Each data has a target which is also presented in the form of vector. The target or reference output is a character map that shows the location of the input vector. Furthermore, the training method is a training process to recognize and store data or information obtained into weights.

There are 3 phases in the BNN training, namely feedforward, backpropagation, and weight modification. In feedforward, the input pattern is calculated forward starting from the input layer to the output layer. In backpropagation, each output unit receives a target pattern related to the input pattern to calculate the error value. The error is propagated backward. Weight modification aims to reduce the errors that occur. The three phases are repeated continuously until the termination condition is met [10][11], 
The Backpropagation Neural Network (BNN) method uses equations 1 to 11 as presented below, [12][12],

Step 0: Initialize all weights with small random numbers

Step 1: If the termination condition has not been met, do steps 2-8

Step 2: For each pair of training data, do steps 3 - 8

Phase 1: Feedforward

Step 3: Each input unit receives a signal and passes it to the hidden unit Step 4: Calculate all outputs in the hidden unit $\left(\mathrm{Z}_{\mathrm{j}}\right)$ :

$$
\begin{aligned}
& z_{n e t_{j}}=v_{0 j}+\sum_{i=1}^{n} x_{i} v_{i j} \\
& z_{j}=f\left(z_{\text {net }_{j}}\right)=\frac{1}{1+e^{-z_{-} \text {net }_{j}}}
\end{aligned}
$$

Notes:

$z_{\text {net }}{ }_{j} \quad=$ hidden unit value of $\mathrm{j}$

$v_{0 j}=$ input layer weight is biased to hia dden unit of $\mathrm{j}$

$x_{i}=$ unit input of $\mathrm{i}$

$v_{i j}=$ unit input weight of $\mathrm{i}$ to the hidden layer of $\mathrm{j}$

$z_{j} \quad=$ hidden unit value of $\mathrm{j}$ using the sigmoid activation function

$e \quad=$ constant value $=2,718$

Step 5: Calculate all networks in output unit $\left(\mathrm{y}_{\mathrm{k}}\right)$

$$
\begin{aligned}
& y_{-} n e t_{k}=w_{0 k}+\sum_{j=1}^{p} z_{j} w_{j k} \\
& y_{k}=f\left(y_{-} n e t_{k}\right)=\frac{1}{1+e^{-y_{-} n e t_{k}}}
\end{aligned}
$$

Notes:

$y_{-}$net $_{k} \quad=$ output value of $\mathrm{k}$

$w_{0 k} \quad=$ hidden unit weight is biased to output unit of $\mathrm{k}$

$w_{j k} \quad=$ hidden unit weight of $\mathrm{j}$ to output unit of $\mathrm{k}$

$y_{k} \quad=$ output unit value of $\mathrm{k}$ using the sigmoid activation function

Phase 2: Backpropagation

Step 6: Calculate the $\delta$ factor of the output unit based on errors in each output unit:

$$
\delta_{k}=\left(t_{k}-y_{k}\right) f^{\prime}\left(y_{-} n e t_{k}\right)=\left(t_{k}-y_{k}\right) y_{k}\left(1-y_{k}\right)
$$

$\delta_{\mathrm{k}}$ is an error to be used in changing the weight of the layer below (step 7) then calculate the weight change rate $\mathrm{w}_{\mathrm{jk}}$ (which is used later to change the weight of $\mathrm{w}_{\mathrm{jk}}$ ) with learning rate $\alpha$. Learning rate is one of the parameters used to calculate the value of weight change with a range between 0 and 1 .

$$
\Delta w_{j k}=\alpha \delta_{k} z_{j}
$$


Notes:

$\delta_{k} \quad=$ A error value of output unit

$t_{k}=$ output target value

$\alpha \quad=$ learning rate

$\Delta w_{j k}=$ weight change of hidden unit of $\mathrm{j}$ to output unit of $\mathrm{k}$

Step 7: Calculate $\delta$ factor of the hidden unit based on an error of each $z_{j}$ hidden unit

$$
\delta_{-} n e t_{j}=\sum_{k=1}^{m} \delta_{k} w_{j k}
$$

$\delta$ error factor of the hidden unit

$$
\delta_{j}=\delta_{-} n e t_{j} f^{\prime}\left(z_{-} n e t_{j}\right)=\delta_{-} n e t_{j} z_{j}\left(1-z_{j}\right)
$$

Calculate weight change rate of $v_{\mathrm{ij}}$ (used to change $v_{\mathrm{ij}}$ )

$$
\Delta v_{i j}=\alpha \delta_{j} x_{i}
$$

Notes:

$\delta_{j} \quad=$ error value of the hidden unit

$\Delta v_{i j}=$ weight change of input unit of $\mathrm{i}$ to hidden unit of $\mathrm{j}$

Phase 3: Weight modification

Step 8: Calculate all weight changes

Weight change towards output unit:

$$
w_{j k}(n e w)=w_{j k}(\text { old })+\Delta w_{j k}
$$

Weight change towards hidden unit:

$$
v_{i j}(\text { new })=v_{i j}(\text { old })+\Delta v_{i j}
$$

Step 9: Finish

Upon the completion of training, it is followed by pattern recognition. In this case, only feedforward (steps 4 and 5) is used to determine the output. If the activation function used is not a binary Sigmoid, step 4 and 5 is adjusted; similarly for step 6 and 7.

The termination condition is met if the iteration is greater than the maximum iteration specified. Iteration is a series of steps in learning neural networks. An iteration is defined as one whole process from step 2 to 8 .

\section{Research methods}

This section encompasses the method used for the study, namely research design, place and time of the study, stages of the study, data collection, system development, and system description.

\subsection{Research Design}


The research design used is quantitative research. Quantitative research aims to describe existing facts and explain the relationship among variables that the data can be further processed by analyzing and interpreting data in testing the statistical hypothesis. The use of the quantitative method is that the data collected are in the form of numbers.

\subsection{Stage of the Study}

The stage of the study consists of 3 parts, namely data collection, implementation of Backpropagation Neural Network (BNN) method, and algorithm testing using a performance test.

\section{a. Data Collection}

The data collection is divided into 2 types, namely primary and secondary data. Primary data were obtained by interviewing the administration staff of Information Systems Study Program and the Technical Implementation Unit of Information Technology of Universitas Jember aiming to obtain study data record of the Information Systems Study Program graduates. Secondary data were obtained by literature reviews through journals and textbooks on data mining, especially classification and backpropagation neural network.

\section{b. Classification Testing}

Classification testing is a test performed on the classification method used. The test is to measure the accuracy level of the data obtained from the method calculation. In this study, the method used is the Backpropagation Neural Network (BNN).

Classification testing used is a performance test which employs the value of accuracy, precision, recall, and F-Measure. Accuracy is the closeness between the predicted value and the actual value. Precision is the accuracy level between the information requested by the user and the answers given by the system. The recall is the success level of the system in rediscovering information. F-measure is an evaluation calculation in information retrieval which combines precision and recall.

The use of the four terms is generally described in the form of the confusion matrix. The confusion matrix is a measuring instrument in the form of a $2 \times 2$ matrix used to measure the accuracy level of the algorithm used. The confusion matrix is presented in Table 1.

Table 1. Confusion matrix

\begin{tabular}{rcc}
\hline Prediction Class & \multicolumn{2}{c}{ Actual Class } \\
\cline { 2 - 3 } & True & False \\
\hline True & TP (True Positive) & FP (False Positive) \\
False & FN(False Negative) & TN (True Negative) \\
\hline
\end{tabular}

Notes:

True Positive (TP): The predicted data is positive and matches the actual value (positive).

False Positive (FP): The predicted data does not match the actual value.

False Negative (FN): The predicted data is negative and the actual value is positive.

True Positive (TN): The predicted and actual values are both negative. 
The measurement of accuracy, precision, recall, and F-Measure based on the confusion matrix is formulated in equation 12 to 16 below.

$$
\begin{array}{ll}
\text { Accuracy } & =\frac{T P+T N}{T P+F N+F P+T N} \\
\text { Precision } & =\frac{T P}{T P+F N} \\
\text { Recall } & =\frac{T P}{T P+F P} \\
\text { F-Measure } & =\frac{2 \times T P}{2 \times T P+F P+F N}
\end{array}
$$

This research used the backpropagation neural network method with 9-3-1 network architecture meaning that the architecture contains 9 neurons at the input layer, 3 neurons in the hidden layer, and 1 neuron at the output layer. The input layer neurons are the attributes found in the student data; the output layer neurons are classes contained in the student data. The researchers used 3 neurons in the hidden layer. The initial stage in this system is the graduate student datasets being normalized using the sigmoid activation function (binary), both all attributes and classes, with intervals [0.1, 0.9]. The formula for the normalization is [12].

$$
x^{\prime}=\frac{0.8(x-a)}{b-a}+0.1
$$

Notes:

$x^{\prime}=$ data value of $\mathrm{n}$ after normalization

$x=$ data value of $\mathrm{n}$

$a=$ minimum data value

$b=$ maximum data value

After normalization, the backpropagation training process starts from feedforward to check for errors followed by backpropagation to correct the weights. The backpropagation process is complete if the termination condition is met. In this study, termination is met if the iteration value reaches the specified maximum iteration limit.

The dataset used in this system uses the full train full test. After the backpropagation training process is complete, the testing process is carried out using the training process dataset to measure performance test using equations 10 to 13 .

System design is a diagram-making system which uses the Unified Modeling Language (UML) with Object-Oriented Programming (OOP). System design includes Business Process, Usecase Diagram, and Entity Relationship Diagram (ERD)[13].

Input element output process is used to describe the input data needed by the system, the system output, and the purpose of system development. Input element output process can be seen in Figure 1. 


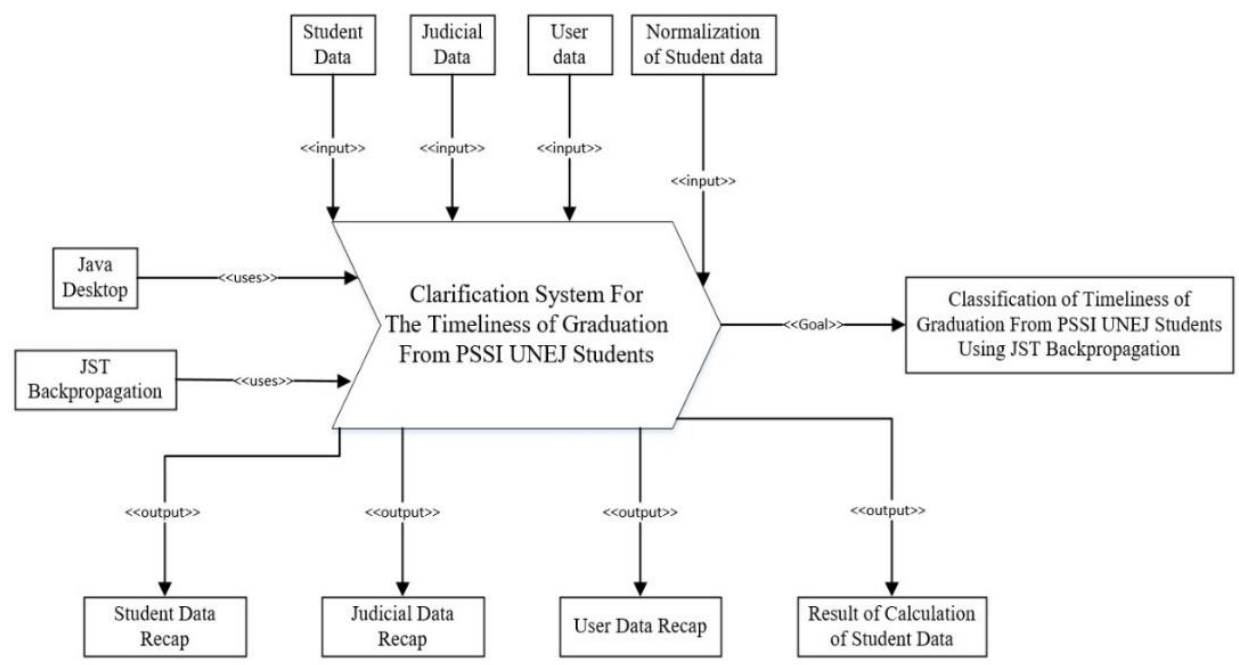

Fig 1. Input Element Output Process

\subsection{Usecase Diagram}

Usecase Diagram is used to describe the features in the classification system for the timeliness of student graduation of Information System Study Program at Universitas Jember using the implementation of backpropagation artificial neural network algorithm. Usecase Diagram can be seen in Figure 2

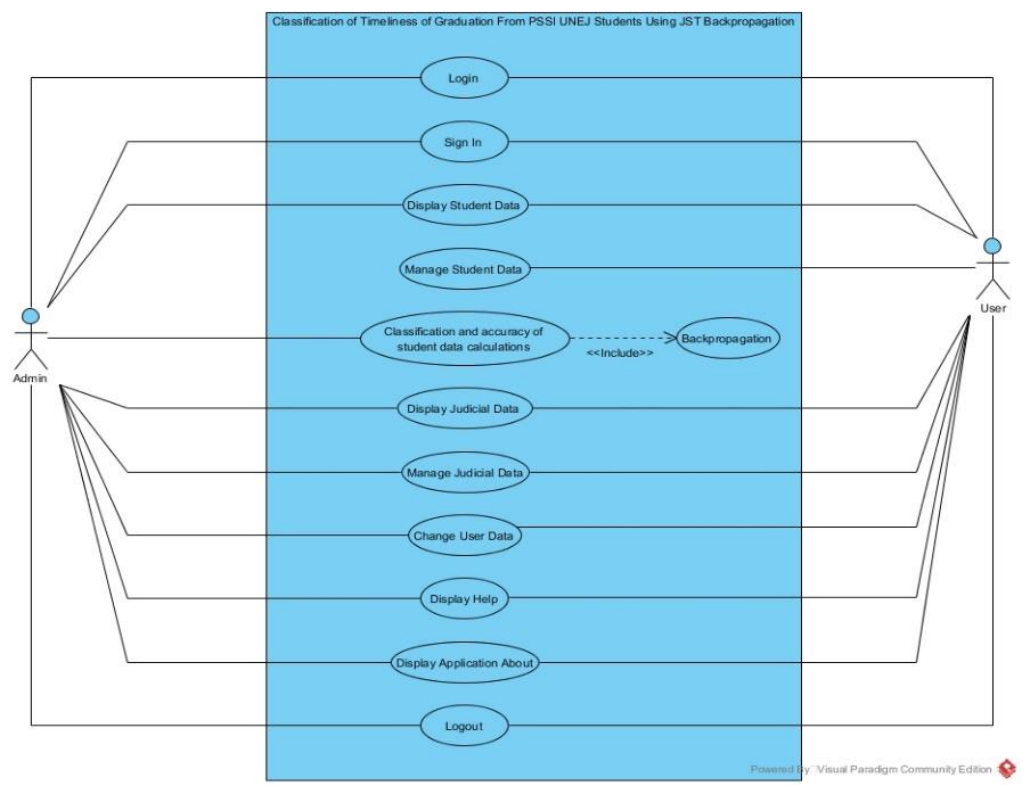

Fig 2. Usecase Diagram 


\section{Result and discussion}

\subsection{Implementation result of backpropagation artificial neural network method}

In this study, the implementation of Backpropagation artificial neural network method was used in the calculation process of the classification of timeliness of student graduation of Information Systems Study Program of Universitas Jember. The calculation was made from the data of the Information Systems graduates which had been obtained from the academic of Information Systems Study Program of Universitas Jember and manager of the Technical Implementation Unit of Information Technology of Universitas Jember.

Prior to the calculation, data cleaning was first conducted to eliminate noise and inconsistent or irrelevant data. From the academic, 314 data records were obtained from 2009. 2013, and 346 records were obtained from the Technical Implementation Unit. Upon the completion of data cleaning, the result obtained was of 169 graduates from 2011-2013, because blank data were found from 2009-2010 meaning that they could not be used for the classification calculation process, namely the GPA from the $1^{\text {st }}-4^{\text {th }}$ semester (for the class of 2009) and $1^{\text {st }}-2^{\text {nd }}$ semester (for the class of 2010). The attribute contains a value of 0.00 because it is not detected by the integrated information system. The data of graduated which have undergone data cleaning can be seen in Table 2.

Table 2. Data of information systems study program graduates of universities member

\begin{tabular}{|c|c|c|c|c|c|c|c|c|c|c|c|}
\hline \multirow{2}{*}{ No } & \multirow{2}{*}{ NIM } & \multicolumn{6}{|c|}{ Grade Point (Semester) } & \multirow{2}{*}{$\begin{array}{l}\text { Semester } \\
\text { when } \\
\text { Program } \\
\text { ming } \\
\text { KKN }\end{array}$} & \multirow{2}{*}{$\begin{array}{l}\text { Semester } \\
\text { when } \\
\text { Program } \\
\text { ming } \\
\text { PKL }\end{array}$} & \multirow{2}{*}{$\begin{array}{c}\text { SK } \\
\text { S }\end{array}$} & \multirow{2}{*}{$\begin{array}{l}\text { Length } \\
\text { of } \\
\text { Study } \\
\text { (Month } \\
\text { ) } \\
\end{array}$} \\
\hline & & 1 & 2 & 3 & 4 & 5 & 6 & & & & \\
\hline 1 & $\begin{array}{c}1124101010 \\
01\end{array}$ & $\begin{array}{c}3.2 \\
0\end{array}$ & $\begin{array}{c}3.2 \\
2\end{array}$ & $\begin{array}{c}3.6 \\
3\end{array}$ & $\begin{array}{c}3.5 \\
4\end{array}$ & $\begin{array}{c}3.5 \\
7\end{array}$ & $\begin{array}{c}3.7 \\
0\end{array}$ & 7 & 7 & 148 & 46.93 \\
\hline 2 & $\begin{array}{c}1124101010 \\
02\end{array}$ & $\begin{array}{c}3.7 \\
5\end{array}$ & $\begin{array}{c}3.6 \\
5\end{array}$ & $\begin{array}{c}3.7 \\
9\end{array}$ & $\begin{array}{c}3.9 \\
2\end{array}$ & $\begin{array}{c}3.8 \\
7\end{array}$ & $\begin{array}{c}4.0 \\
0\end{array}$ & 7 & 6 & 148 & 46.5 \\
\hline 3 & $\begin{array}{c}1124101010 \\
03\end{array}$ & $\begin{array}{c}2.2 \\
5\end{array}$ & $\begin{array}{c}2.8 \\
3\end{array}$ & $\begin{array}{c}2.9 \\
5\end{array}$ & $\begin{array}{c}2.8 \\
1\end{array}$ & $\begin{array}{c}3.1 \\
0\end{array}$ & $\begin{array}{c}3.3 \\
5\end{array}$ & 8 & 7 & 146 & 52.1 \\
\hline 4 & $\begin{array}{c}1124101010 \\
05\end{array}$ & $\begin{array}{c}2.6 \\
0\end{array}$ & $\begin{array}{c}2.9 \\
0\end{array}$ & $\begin{array}{c}2.2 \\
9\end{array}$ & $\begin{array}{c}2.4 \\
4\end{array}$ & $\begin{array}{c}3.1 \\
1\end{array}$ & $\begin{array}{c}3.2 \\
1\end{array}$ & 8 & 7 & 147 & 46.73 \\
\hline 5 & $\begin{array}{c}1124101010 \\
07\end{array}$ & $\begin{array}{c}3.3 \\
0\end{array}$ & $\begin{array}{c}3.7 \\
4\end{array}$ & $\begin{array}{c}3.7 \\
1\end{array}$ & $\begin{array}{c}3.5 \\
4\end{array}$ & $\begin{array}{c}3.8 \\
1\end{array}$ & $\begin{array}{c}3.5 \\
0\end{array}$ & 7 & 6 & 148 & 69.23 \\
\hline 6 & $\begin{array}{c}1124101010 \\
08\end{array}$ & $\begin{array}{c}3.5 \\
5\end{array}$ & $\begin{array}{c}3.1 \\
7\end{array}$ & $\begin{array}{c}3.6 \\
7\end{array}$ & $\begin{array}{c}3.2 \\
9\end{array}$ & $\begin{array}{c}3.1 \\
4\end{array}$ & $\begin{array}{c}3.7 \\
3\end{array}$ & 7 & 7 & 148 & 49.57 \\
\hline 7 & $\begin{array}{c}1124101010 \\
11\end{array}$ & $\begin{array}{c}3.1 \\
0\end{array}$ & $\begin{array}{c}3.0 \\
0\end{array}$ & $\begin{array}{c}3.2 \\
1\end{array}$ & $\begin{array}{c}2.5 \\
0\end{array}$ & $\begin{array}{c}3.4 \\
8\end{array}$ & $\begin{array}{c}3.5 \\
0\end{array}$ & 7 & 6 & 148 & 51.13 \\
\hline 8 & $\begin{array}{c}1124101010 \\
12\end{array}$ & $\begin{array}{c}2.4 \\
5\end{array}$ & $\begin{array}{c}2.2 \\
2\end{array}$ & $\begin{array}{c}2.5 \\
0\end{array}$ & $\begin{array}{c}3.0 \\
0\end{array}$ & $\begin{array}{l}26 \\
3 .\end{array}$ & $\begin{array}{c}3.2 \\
4\end{array}$ & 8 & 7 & 147 & 63.80 \\
\hline 9 & $\begin{array}{c}1124101010 \\
13\end{array}$ & $\begin{array}{c}2.3 \\
0\end{array}$ & $\begin{array}{c}3.0 \\
0\end{array}$ & $\begin{array}{c}3.0 \\
4\end{array}$ & $\begin{array}{c}3.1 \\
3\end{array}$ & $\begin{array}{c}3.2 \\
6\end{array}$ & $\begin{array}{c}3.1 \\
7\end{array}$ & 8 & 7 & 147 & 52.1 \\
\hline 10 & $\begin{array}{c}1124101010 \\
15\end{array}$ & $\begin{array}{c}3.1 \\
0\end{array}$ & $\begin{array}{c}3.1 \\
7\end{array}$ & $\begin{array}{c}2.8 \\
8\end{array}$ & $\begin{array}{c}3.0 \\
5\end{array}$ & $\begin{array}{c}3.3 \\
5\end{array}$ & $\begin{array}{c}3.7 \\
0\end{array}$ & 8 & 6 & 148 & 52.1 \\
\hline$\cdots$ & $\cdots$ & $\cdots$ & $\ldots$ & $\cdots$ & $\cdots$ & $\ldots$ & $\ldots$ & $\cdots$ & $\cdots$ & $\ldots$ & $\ldots$ \\
\hline
\end{tabular}




\begin{tabular}{cccccccccccc}
16 & 1324101010 & 3.6 & 3.3 & 3.4 & 3.3 & 3.3 & 3.6 & 7 & 7 & 145 & 44.57 \\
9 & 92 & 0 & 0 & 8 & 6 & 9 & 0 & & \\
\hline
\end{tabular}

The classification of timeliness of student graduation is based on the study period of each student. For the undergraduate program, students must pass 144 credits of 4-5 years study period. Thus, students are classified as graduating on time if their study period is less than or equal to 5 years (60 months). If it is more than 5 years (60 months), it is not classified as on time. The classification based on a study period is presented in Table 3.

Table. 3 classification based on a study period

\begin{tabular}{cccc}
\hline No. & Length of Study & Classification & Classification Value \\
\hline 1 & Less than or equal to 60 months & On Time & 1 \\
2 & More than 60 months & Not On Time & 2 \\
\hline
\end{tabular}

After data cleaning, the data were normalized using the sigmoid activation function (binary) both in terms of the attributes and the class with an interval of [0.1, 0.9]. Based on equation 14, the minimum and maximum value of each attribute and class are shown in Table 4 and the normalization result is shown in Table 5.

Table 4. Minimum and maximum value of each attribute and class

\begin{tabular}{clcc}
\hline No. & \multicolumn{1}{c}{ Attribute/Class } & $\begin{array}{c}\text { Minimum } \\
\text { Value }\end{array}$ & $\begin{array}{c}\text { Maximum } \\
\text { Value }\end{array}$ \\
\hline 1 & Semester 1 Grade Point & 0 & 4 \\
2 & Semester 2 Grade Point & 0 & 4 \\
3 & Semester 3 Grade Point & 0 & 4 \\
4 & Semester 4 Grade Point & 0 & 4 \\
5 & Semester 5 Grade Point & 0 & 4 \\
6 & Semester 6 Grade Point & 0 & 4 \\
7 & Semester when the student last took KKN courses & 7 & 9 \\
8 & Semester when the student last took PKL courses & 6 & 9 \\
9 & Number of credits taken & 144 & 153 \\
10 & Class & 1 & 2 \\
\hline
\end{tabular}

Table 5. Normalization of student data

\begin{tabular}{ccccccccccccc}
\hline No. & NIM & $\begin{array}{c}\text { Semes } \\
\text { ter 1 } \\
\text { Grade }\end{array}$ & $\begin{array}{c}\text { Semes } \\
\text { ter 2 } \\
\text { Grade }\end{array}$ & $\begin{array}{c}\text { Semes } \\
\text { ter 3 } \\
\text { Grade }\end{array}$ & $\begin{array}{c}\text { Semes } \\
\text { ter 4 } \\
\text { Grade }\end{array}$ & $\begin{array}{c}\text { Semes } \\
\text { ter 5 } \\
\text { Grade }\end{array}$ & $\begin{array}{c}\text { Semes } \\
\text { ter 6 } \\
\text { Grade }\end{array}$ & $\begin{array}{c}\text { KKN } \\
\text { Semes } \\
\text { ter }\end{array}$ & $\begin{array}{c}\text { PKL } \\
\text { Semes } \\
\text { ter }\end{array}$ & Credits & Class \\
\hline 1 & 112410 & 0.740 & 0.744 & 0.826 & 0.808 & 0.814 & 0.840 & 0.100 & 0.367 & 0.456 & 0.1 \\
& 101001 & & & & & & & & & & \\
2 & 112410 & 0.850 & 0.830 & 0.858 & 0.884 & 0.874 & 0.900 & 0.100 & 0.100 & 0.456 & 0.1 \\
& 101002 & & & & & & & & & & & \\
3 & 112410 & 0.550 & 0.666 & 0.690 & 0.662 & 0.720 & 0.770 & 0.500 & 0.367 & 0.278 & 0.1 \\
4 & 101003 & & & & & & & & & & \\
4 & 112410 & 0.620 & 0.680 & 0.558 & 0.588 & 0.722 & 0.742 & 0.500 & 0.367 & 0.367 & 0.1
\end{tabular}




\begin{tabular}{|c|c|c|c|c|c|c|c|c|c|c|c|}
\hline 5 & $\begin{array}{l}112410 \\
101007\end{array}$ & 0.760 & 0.848 & 0.842 & 0.808 & 0.862 & 0.800 & 0.100 & 0.100 & 0.456 & 0.9 \\
\hline 6 & $\begin{array}{l}112410 \\
101008\end{array}$ & 0.810 & 0.734 & 0.834 & 0.758 & 0.728 & 0.846 & 0.100 & 0.367 & 0.456 & 0.1 \\
\hline 7 & $\begin{array}{l}112410 \\
101011\end{array}$ & 0.720 & 0.700 & 0.758 & 0.600 & 0.796 & 0.800 & 0.100 & 0.100 & 0.456 & 0.1 \\
\hline 8 & $\begin{array}{l}112410 \\
101012\end{array}$ & 0.590 & 0.544 & 0.600 & 0.700 & 0.626 & 0.748 & 0.500 & 0.367 & 0.367 & 0.9 \\
\hline 9 & $\begin{array}{l}112410 \\
101013\end{array}$ & 0.560 & 0.700 & 0.708 & 0.726 & 0.752 & 0.734 & 0.500 & 0.367 & 0.367 & 0.1 \\
\hline 10 & $\begin{array}{l}112410 \\
101015\end{array}$ & 0.720 & 0.734 & 0.676 & 0.710 & 0.770 & 0.840 & 0.500 & 0.100 & 0.456 & 0.1 \\
\hline$\ldots$ & $\ldots$ & $\ldots$ & $\ldots$ & $\ldots$ & $\ldots$ & $\ldots$ & $\ldots$ & $\ldots$ & $\ldots$ & $\ldots$ & $\ldots$ \\
\hline 169 & $\begin{array}{l}132410 \\
101092\end{array}$ & 0.820 & 0.760 & 0.796 & 0.772 & 0.778 & 0.820 & 0.100 & 0.367 & 0.189 & 0.1 \\
\hline
\end{tabular}

\subsection{Performance testing}

Performance testing was performed to measure the Backpropagation artificial neural network method in classifying the timeliness of the student graduation in terms of accuracy, precision, recall, and F-Measure[14]. Testing was by analyzing the predicted class value for learning rate of $0.1,0.3,0.5,0.7$, and 0.9 with iteration limits of $1,000,2,000$ and 3,000. The result of accuracy, precision, recall, and F-Measure can be seen in Table 6 to 9

Table 6. Accuracy value

\begin{tabular}{clllll}
\hline Iteration & \multicolumn{5}{c}{ Learning Rate } \\
Limit & 0.1 & 0.3 & 0.5 & 0.7 & 0.9 \\
\hline 1000 & $95.27 \%$ & $95.86 \%$ & $95.86 \%$ & $95.86 \%$ & $95.86 \%$ \\
2000 & $97.63 \%$ & $97.04 \%$ & $97.04 \%$ & $98.82 \%$ & $98.82 \%$ \\
3000 & $97.63 \%$ & $97.04 \%$ & $98.82 \%$ & $98.82 \%$ & $98.82 \%$ \\
\hline
\end{tabular}

Table 7. Precision value

\begin{tabular}{cccccc}
\hline Iteration & \multicolumn{5}{c}{ Learning Rate } \\
Limit & 0.1 & 0.3 & 0.5 & 0.7 & 0.9 \\
\hline 1000 & $95.63 \%$ & $95.65 \%$ & $95.65 \%$ & $95.65 \%$ & $95.65 \%$ \\
2000 & $97.47 \%$ & $96.86 \%$ & $96.86 \%$ & $98.72 \%$ & $98.72 \%$ \\
3000 & $97.47 \%$ & $96.86 \%$ & $98.72 \%$ & $98.72 \%$ & $98.72 \%$ \\
\hline
\end{tabular}

Table 8. Recall value

\begin{tabular}{crrrrr}
\hline Iteration & \multicolumn{5}{c}{ Learning Rate } \\
Limit & 0.1 & 0.3 & 0.5 & 0.7 & 0.9 \\
\hline 1000 & $99.35 \%$ & $100.00 \%$ & $100.00 \%$ & $100.00 \%$ & $100.00 \%$ \\
2000 & $100.00 \%$ & $100.00 \%$ & $100.00 \%$ & $100.00 \%$ & $100.00 \%$ \\
3000 & $100.00 \%$ & $100.00 \%$ & $100.00 \%$ & $100.00 \%$ & $100.00 \%$ \\
\hline
\end{tabular}


Table 9. F-measure value

\begin{tabular}{cccccc}
\hline Iteration & \multicolumn{5}{c}{ Learning Rate } \\
Limit & 0.1 & 0.3 & 0.5 & 0.7 & 0.9 \\
\hline 1000 & $97.45 \%$ & $97.78 \%$ & $97.78 \%$ & $97.78 \%$ & $97.78 \%$ \\
2000 & $98.72 \%$ & $98.40 \%$ & $98.40 \%$ & $99.35 \%$ & $99.35 \%$ \\
3000 & $98.72 \%$ & $98.40 \%$ & $99.35 \%$ & $99.35 \%$ & $99.35 \%$ \\
\hline
\end{tabular}

Based on Table 6 to 9, it can be concluded that the use of Backpropagation neural network method for classification of timeliness of the student graduation is of high accuracy, precision, recall, and F-Measure. The highest accuracy value is $98.82 \%$ in the $2000^{\text {th }}$ and $3000^{\text {th }}$ iteration, with learning rate $=0.7$ and 0.9 for the $2000^{\text {th }}$ iteration and learning rate $=0.5$, 0.7 , and 0.9 for $3000^{\text {th }}$ iteration. The accuracy value is obtained from the correct data of 167 out of 169 total data. The highest precision value is of $98.72 \%$ in the $2000^{\text {th }}$ and $3000^{\text {th }}$ iteration, with learning rate $=0.7$ and 0.9 for the $2000^{\text {th }}$ iteration and learning rate $=0.5,0.7$, and 0.9 for the $3000^{\text {th }}$ iteration. The highest recall value is of $100.00 \%$ for all learning rate and iteration limits, except for learning rate $=0.1$ for the $1000^{\text {th }}$ iteration of $99.35 \%$. The highest $\mathrm{F}$ Measure value is of $99.35 \%$ in the $2000^{\text {th }}$ and $3000^{\text {th }}$ iterations, with learning rate $=0.7$ and 0.9 for the $2000^{\text {th }}$ iteration and learning rate $=0.5,0.7$ and 0.9 for the $3000^{\text {th }}$ iteration.

\section{Conclusion}

The use of Backpropagation neural network method for classification of timeliness of the student graduation is of high accuracy, precision, recall, and F-Measure. The highest accuracy value is $98.82 \%$ in the $2000^{\text {th }}$ and $3000^{\text {th }}$ iteration, with learning rate $=0.7$ and 0.9 for the $2000^{\text {th }}$ iteration and learning rate $=0.5,0.7$, and 0.9 for $3000^{\text {th }}$ iteration. The accuracy value is obtained from the correct data of 167 out of 169 total data. The highest precision value is of $98.72 \%$ in the $2000^{\text {th }}$ and $3000^{\text {th }}$ iteration, with learning rate $=0.7$ and 0.9 for the $2000^{\text {th }}$ iteration and learning rate $=0.5,0.7$, and 0.9 for the $3000^{\text {th }}$ iteration. The highest recall value is of $100.00 \%$ for all learning rate and iteration limits, except for learning rate $=0.1$ for the $1000^{\text {th }}$ iteration of $99.35 \%$. The highest F-Measure value is of $99.35 \%$ in the $2000^{\text {th }}$ and $3000^{\text {th }}$ iterations, with learning rate $=0.7$ and 0.9 for the $2000^{\text {th }}$ iteration and learning rate $=$ $0.5,0.7$ and 0.9 for the $3000^{\text {th }}$ iteration.

The implementation of the Backpropagation neural network method in the classification system of the timeliness of student graduation of Information Systems Study Program of Universitas Jember was carried out in several steps. The first step was to collect data from the administrative staff of Information Systems Study Program of Universitas Jember and the Technical Implementation Unit of Information Technology of Universitas Jember. The second step is to do data cleaning in order to eliminate noise and inconsistent or irrelevant data, resulting in 169 data records of the graduates from $2011-2013$. The third step is to calculate the Backpropagation method. The architecture used in the Backpropagation neural network is 9-3-1 which means that the architecture contains 9 neurons at the input layer, 3 neurons in the hidden layer, and 1 neuron at the output layer. The input layer neurons include the attributes in the student data, namely GPA from $1^{\text {st }}-6^{\text {th }}$ semester, credit units, and the last semester taking Student Study Service $(\mathrm{KKN})$ and Internship (PKL). The output layer neurons include the class in the student data, assuming that if the study period is less than or equal to 60 months, the student graduates on time, and vice versa.

The suggestion is that further study can add more attributes, such as leave attribute and thesis attribute to determine the effect of the accuracy level of the classification. Besides, adding more neurons in the hidden layer can help determine the accuracy level of the classification 


\section{References}

[1] Han, Jiawei., and Micheline. Kamber. Data Mining : Concepts and Techniques. Morgan Kaufmann Publishers,

https://www.google.co.id/search?q=Han\%2C+J.+and+Kamber\%2C+M.+(2006).+Data+ Mining\%3A+Concepts+and+Techniques.+The+Morgan+Kaufmann+series+in+data+ma nagement+systems.+Elsevier+San+Francisco+(Calif.)\%2C+Amsterdam\%2C+Boston\%2 $\mathrm{C}+$ Heidelberg\&oq=Han\%2C+J.+and+Kambe.

[2] Gorunescu, Florin. Data Mining: Concepts, Models and Techniques. Statewide $\begin{array}{llll}\text { Agricultural Land } \quad \text { Use } & \text { Baseline } & \text { 2015, }\end{array}$ https://doi.org/10.1017/CBO9781107415324.004.

[3] Ridwan, M., Suyono, H., \& Sarosa, M. (2013). Penerapan Data Mining untuk Evaluasi Kinerja Akademik Mahasiswa Menggunakan Algoritma Naive Bayes Classifier. Jurnal EECCIS, 1(7), 59-64.

[4] Taruna R., S., \& Hiranwal, S. (2013). Enhanced Naive Bayes Algorithm for Intrusion Detection. International Journal of Computer Science and Information Technologies, 6(4), 960-962.

[5] Nurdiansyah, Y., S. Bukhori, and R. Hidayat, "Sentiment Analysis System for Movie Review in Bahasa Indonesia Using Naive Bayes Classifier Method," in Journal of Physics: Conference Series, 2018, mviii https://doi.org/10.1088/1742$6596 / 1008 / 1 / 012011$

[6] Nugroho, Y. S. (2013). Data Mining Menggunakan Algoritma Nä̈ve Bayes Untuk Klasifikasi Kelulusan Mahasiswa Universitas Dian Nuswantoro.

[7] Dharwal, Rajan, and Loveneet Kaur. "Applications of Artificial Neural Networks: A Review.” Indian Journal of Science and Technology 9, no. 47 (December 28, 2016). https://doi.org/10.17485/IJST/2016/V9I47/106807.

[8] Chattopadhyay, Surajit, and Goutami Bandyopadhyay. "Artificial Neural Network with Backpropagation Learning to Predict Mean Monthly Total Ozone in Arosa, Switzerland." International Journal of Remote Sensing 28, no. 20 (October 20, 2007): 4471-82. https://doi.org/10.1080/01431160701250440.

[9] Leone, R. De, R. Capparuccia, and E. Merelli. "A Successive Overrelaxation Backpropagation Algorithm for Neural-Network Training." IEEE Transactions on Neural Networks 9, no. 3 (May 1998): 381-88. https://doi.org/10.1109/72.668881.

[10] Fu, Sha, and Guo-Bing Fan. "A Multiple Attribute Decision-Making Method Based on Exponential Fuzzy Numbers.” Accessed October 2, 2018. https://doi.org/10.3390/mca21020019.

[11] Ding, Tao, Liang Liang, Min Yang, and Huaqing Wu. "Multiple Attribute Decision Making Based on Cross-Evaluation with Uncertain Decision Parameters." Mathematical Problems in Engineering 2016 (April 27, 2016): 1-10. https://doi.org/10.1155/2016/4313247.

[12] Siang, J. J. (2009). Jaringan Syaraf Tiruan dan Pemrogramannya Menggunakan Mathlab. Yogyakarta: Pen.

[13] Sofian, Ian Mochamad, Azhar Kholiq Affandi, Iskhaq Iskandar, Yosi Apriani, and Yosi Apriani. "Monthly Rainfall Prediction Based on Artificial Neural Networks with Backpropagation and Radial Basis Function." International Journal of Advances in $\begin{array}{lllllll}\text { Intelligent Informatics } 4, \quad \text { no. } 2 & \text { (July } & 31, & 2018): & 154 .\end{array}$ https://doi.org/10.26555/ijain.v4i2.208.

[14] McMurtrey, Mark, "A Case Study of the Application of the Systems Development Life Cycle (SDLC) in 21st Century Health Care: Something Old, Something New?," Journal 
of the Southern Association for Information Systems, 1 (2013) https://doi.org/10.3998/jsais.11880084.0001.103.

[15] Saputra, Laurentius Kuncoro Probo, Hanung Adi Nugroho, and Meirista Wulandari. "Feature Extraction and Classification of Heart Sound Based on Autoregressive Power Spectral Density (AR-PSD).” In 2014 The 1st International Conference on Information Technology, Computer, and Electrical Engineering, 139-43. IEEE, 2014. https://doi.org/10.1109/ICITACEE.2014.7065730. 